\title{
5 The Impact of psychological anxiety on academic achievement in A'Sharqiyah University in the Sultanate of Oman
}

Dr. Esam A Majeed Al lawati, Assistant Professor of Psychology, Head of Psychology Department, A'Sharqiyah University, OMAN.email: esam.allawati@asu.edu.om

\begin{abstract}
Psychological stability plays an extremely important role in student life and affects his/her academic performance, it impacts their attitude, performance and exams. Current research highlighted on impacting the level of anxiety towards academic achievement in the A'Sharqiyah University in Oman. The investigation to find out an important association of anxiety and academic achievement was done among A'Sharqiyah University students and for various scientific specializations. A total 308 from both gender student engage in current test. They were from the first year to last year and for both morning and evening students. To measure the level of Anxiety, the researcher used State Trait Anxiety Inventory (STAI) and to measure students' academic achievement, the researcher used students GPA (Grade Point Average). The result of the current study showed that there is a tightly bound correlation between level of Apprehension and academic achievement in different specialization in A' Sharqiyah University. To conduct further studies on the topic, the current study suggested increasing the size of the study sample to enhance the correlation coefficient.
\end{abstract}

Key words: Psychological anxiety, Academic achievement, Students, A'Sharqiyah University, Oman

\section{Overview}

Everyone has anxiety at some point in his/her life, whether preparing him/her self for a personal interview or driving test or when a person has a chronic disease such as diabetes, and the like. The university student in general faces multiple and different challenges during his/her university studies. Therefore, many students suffer from psychological anxiety. Therefore, we can describe anxiety as feelings of distress, tensions and worry that is concomitant with excitation of the nervous system (Mental Health Foundation, 2014) 


\section{(C) Dr. Esam A Majeed Al lawati}

Several investigators have revealed that high anxiety cause to encounter several life troubles such as facing problems how to adopt with a life or privation of opportunities in the future, and affect the life security also the abilities of nature thinking. Often, anxiety leads to behavioral disturbances, as well as to emotional disturbances and impairment in social relationships (Rachel and Chidsey, 2005). Many local, or international studies show those students who have a high level of anxiety are affected by the level of concentration in the classroom, during reading or scientific review, or in the absorption process, as well as the level of students is affected by the extent of their participation in the curricular and non-curricular activities.

People differ in symptoms of anxiety, but the body's interaction with anxiety is usually characterized equally, as it begins the journey of thinking, feeling tired, sense of incapable and impairment in his/her confidence in many aspects of life, while the physiological symptoms are manifested in many aspects, such as heavy sweating, especially in the hands and face, also hyperventilation (rapid breathing) with digestive disturbance; lack consideration to accomplish tasks, and so (Ruffins, 2007).

The phenomenon of worry between high education students is one of the phenomena that both university professors, supervisors and administrators emphasize, and this psychological status cannot overlooked, Therefore, the researcher seeks to identify the importunate of anxiety, and how dangerous it is for a person's mental health and especially university students.

\section{The effect of anxiety on the lives of individuals}

When an individual encounters a problem in his/her life, be it real or from his/her thinking, this leads to changes in his/her own systems which are:

The way of his/her thinking (Cognitive component), the way of the body reacts to the status (Physical component) and finally how individuals behave (behavioural component).

Cognitive component: Interest is represented by some phenomena such as attention, as this attention turns into a potential threat. The effect of thinking on human anxiety varies from moderate to severe with moderate anxiety considered as somewhat natural so that no individual is not anxious in a period of his life, while severe anxiety is considered very dangerous to human life. 


\section{(C) Dr. Esam A Majeed Al lawati}

Physical component: This kind of component is included irregular heartbeat or reduction /growth of heart rate, insignificant in respiration, shake involuntarily, perspiration, get daze, feel tired, feel cool, muscle tensity, feel difficult for breath and queasiness.

Behaviour component: To protect the individual himself from anxiety, we find that he performs some behaviors and avoids some behaviors, and the best example we can observe is the individual avoids passing through some areas that are usually empty and are completely dark.

It is worth noting and paying attention to mention that these three response systems mentioned above are related to anxiety, which is cognitive, physical, and behavioral, they often change in a correlative way, meaning that when they change together. (Alqraiti, 1998).

Many studies have proven that anxiety affects students in general, and university and college students in particular, and therefore, the effect of this anxiety affects academic achievement for them. (McCraty, et al., 2000)

There are several university instructors do not know how anxiety affect students' performance; where many of the results of the studies concluded that the high anxiety of the university student has a negative impact on academic achievement and vice versa. The results of the studies reached further than that, as the results of some of these studies have find out there is a correlation among the levels of apprehension, and the fading level of thinking where the higher the level of anxiety of the university student, the higher his thinking is incomplete and weak (Aronenet al., 2005)

Researchers have found the extent of the effect of anxiety on academic achievement, and the effect includes high school students, where the results of studies have found that the high level of anxiety of a student at the secondary level affects negatively the achievement level. (McCraty, 2007) Correspondingly, they found that student who have a high level of anxiety is characterized by deficiency retention of information and influence of self-confidence, which becomes significantly weakened. In overalls students with lower levels in their academic performance has a high level of anxiety (Sena et al., 2007). 


\section{(C) Dr. Esam A Majeed Al lawati}

\section{Anxiety}

The basis of the term "anxiety" is due to the ancient Gree k"angere", which means causing distress. Among the other definitions of the term anxiety is "the individual's feeling of discomfort, that is, the individual's feeling of ambiguity about a particular situation, and usually this situation causes him to threaten his future." (Sharma \& Sharma, 2015)

The anxiety feature is one of the natural characteristics of different individuals, whether male or female, and anxiety includes various aspects of life such as health and financial issues, social and family issues, and so on. However, some individuals are concerned about the most basic issues of daily life, which are very normal, leading them to isolation or away from people and contentment with him/her self, and the matter does not stop to this extent, but he/she has a negative view in life by believing that things will get worse, and any situation in his/her life is ambiguous and challenging, which causes him/her very high anxiety. (Pascarella \& Terenzini, 2005)

Anxiety, especially excessive anxiety, is characterized by having negative effects on an individual's growth and affecting the performance of various aspects of individual life. There are different types of anxiety that afflict individuals, including social anxiety, which is usually caused by social relationships and social lifestyle, and financial anxiety, this type of anxiety affects individuals in financial terms, such as the financial deficit, or lack of money, or even abundance Money leads to irrational thinking. Also, there is academic anxiety that usually affects students, which is the fear of study, its results and the extent of its impact on the future life. (Brook \& Willoughby, 2015)

Anxiety is widespread among college students. For example, the degree of anxiety among college students in the United States ranges between $10 \%$ to $33 \%$, and the anxiety rate among the general public range from $7 \%$ to $13 \%$. To encounter standard for an anxiety turmoil problem, the person should experiment the immoderate anxiety and unease that he/she discovers intractable to dominance for at least six months to the extent which it causes important tribulation or weakness in functioning(Russell \& Shaw, 2009)

The person has to undergo more than three symptoms which are determined according to the following: Lack of sleep due to sleep disturbances, discomfiture in concentrating, restlessness, exhausted, and 


\section{(C) Dr. Esam A Majeed Al lawati}

irritability. Many individuals increase an anxiety disturbance when they were a child and frequently go untreated, rising the symptoms and passive effects to persevere and conspicuous in dissimilar forms.

Males do not differ from females regarding causing anxiety, as both males and females are at the risk of developing anxiety disorders. As for the percentage of difference of anxiety between the developed countries, and the third world countries, the results showed that individuals in the developed and industrialized countries are more exposed to anxiety disorders than the third world countries. (Emilien, Durlach, \& Lepola, 2002)

Immoderate worry creates difficulties in the capability to do things worthwhile and at the right time. The time and vitality that is having been used about anxiety would leave less time to study or write assignments and it will affect negatively an individual in other approaches. Some other researchers have been explained how untreated anxiety with young adults or even with adolescents will cause many mental, physical, and behavioural illnesses. (Mahmoud, Staten, Lennie, \& Hall, 2015)

In this field, one of the studies examined the effect of anxiety on the achievement results of university students (2015) which investigate instructors/ professors, administrative staffs and parents, too much anxiety has been related with academic achievement, including deficiencyin GPA grades and academic achievement. Supplement assignments, To obtain the completion of the tasks assigned to him / her, perform all homework, submit reports, whether orally or in writing, participate in class work, submit tests are some educational tasks that may show entire academic performance (Nail et al., 2015).

These tasks are affected by the anxiety disorder factor, and the result appears clear to university students. If the anxiety of university students is neglected, this will affect the imbalance of skills and knowledge and thus, affect the development process.

The best example of this is when neglecting the anxiety of an individual was a child, especially in the mid secondary school, which is considered adolescence stage, Its effect appears later on the individual, such as taking sedatives, which may develop into drug use, and alcohol consumption. On the other hand, we notice the extent of the university student's influence on some aggressive behaviors, as well as his/her ability to interact with the university's academic staff, and ultimately affecting the academic achievement. (Gougen, 2010). 


\section{(C) Dr. Esam A Majeed Al lawati}

Another study dealt with the types of anxiety and its impact on the lives of individuals. These types are represented in anxiety state and anxiety traits. The study indicated that both types have a clear impact on students' academic achievement. The anxiety state has been defined as the emotional state of the individual during his/her response to a specific situation which carries specific symptoms such as fear, tension, and stimulation of the nervous system in an unconscious manner, which causes perspiration and hypertension. The concept of trait anxiety indicates the individual's tendency to respond to worry, and the study found that both types "state anxiety and trait anxiety" have positive effects on the individual condition of the student, provided that the state of anxiety does not rise above the average level, meaning that it is not high. Either If the level of anxiety exceeds more than the average, it will lead to a decrease in the academic level of the student. This result indicates that a high level of stress would have counterproductive, and dangerous consequences for an individual's life (Fosterling \& Binser, 2002).

The anxiety perception and academic accomplishment is assumed from the theory of Catastrophe which clarifies the affiliation of apprehension and accomplishment with reference to sports accomplishment. It is essential to comprehend the concept and the impact of apprehension to accomplishment. Martin in Robb (2005) suggested that mental apprehension would have a passive association with accomplishment and physiological apprehension has a wavy association with accomplishment.

This is what (Hamzah, 2007) pointed out in his study. When the level of physiological arousal decreases, it witnesses a positive relationship between cognitive anxiety and the level of performance. While the results showed those students who suffer from a high level of anxiety disorder, they tend, accordingly, to decrease their level of academic achievement.

Resemblance result finds, a convenient number of studies have found a considerable relation among academic achievement and apprehension, a favourable relationship among rising degrees of academic achievement and poor apprehension (El-Anzi, 2005). Next figure interprets this results 


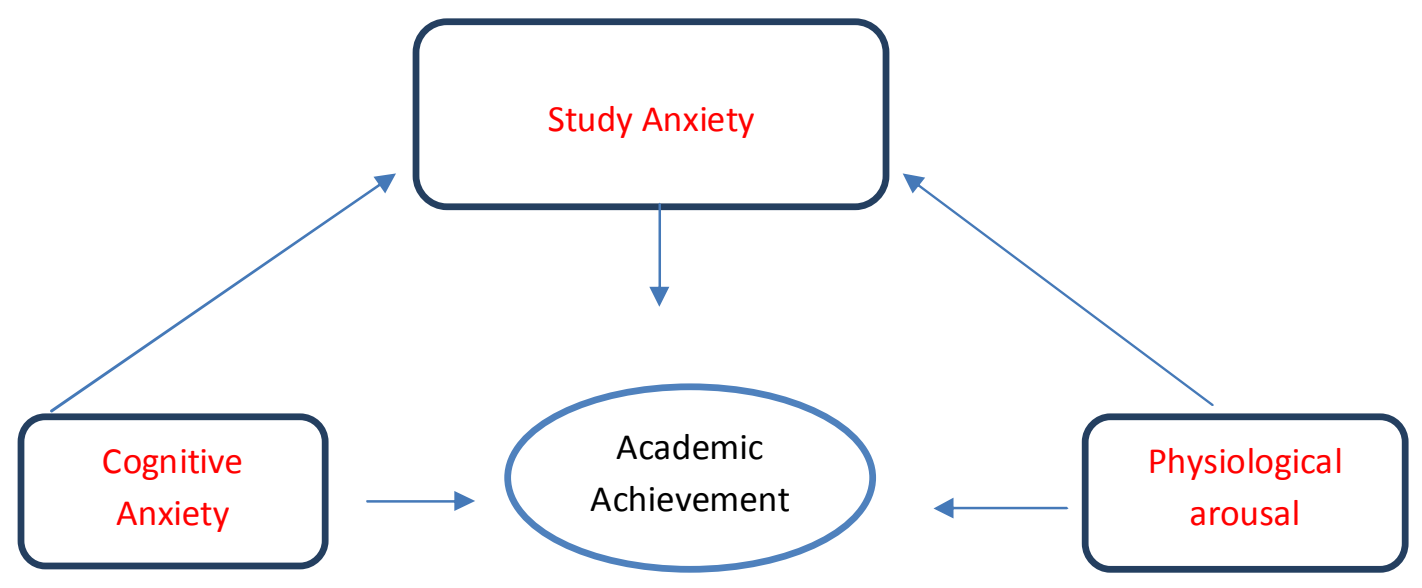

The theoretical paradigm of study anxiety upon academic achievement

The researcher in current study used state and trait instrument (STAI), in order to measure the level of anxiety of A'Sharqiyah university students, which means the level of high or low level of cognitive anxiety is determined by the high scoresof state and trait. The researcher believed that many factors affect student's achievement in Universities such ascommitment to attend classes, ways to interact with colleagues and peers, the role of the university environment, university services and facilities and teaching methods used.

\section{Method}

\section{Participants}

The population in current study are entire A'Sharqiyah University undergraduate students in Ibra governorate in Sultanate of Oman. The researcher conduct a test for measuring student's anxiety level. A total 308 students with poor academic achievement they were included in the test; Students extradite (STAI) instrument for ascertaining anxiety level. Sample in the study was the low students' academic achievement with CGPA less than (2.00) and high level of anxiety with STAI more than 70. 


\section{(C) Dr. Esam A Majeed Al lawati}

\section{Measurement}

The validity and reliability of the instrument have been verified, the reliability of the instrument was about 0.7 , according to what Nunnally (1978) indicated. The validity test of the instrument that is explained by the interconnectedness of the substances according to (Sekaran, 2003) must be more than or equal to 0.30 .

\section{Description of the study instrument (STAI)}

In order to measure the level of anxiety of university students, the researcher used a State Trait Anxiety Inventory scale (STAI) which is belonged to Charlies D. Spielberger (1977), the researcher has modified some phrases of the scale to be appropriate to the local environment. Then he presented it to some professors of psychology in the University for Review, then the researcher applied it to an experimental sample to measure the reliability. The instrument has total (40) phrases, distributed to (2) subscales, each subscale has (20) phrases. First subscale (S-anxiety) consists twenty phrases that assess how students feel anxiety presently, the phrases emphasize the student to write each phrase separately, describing the strength and intensity of his/her feelings. The scale has four answers which the student have to select only one answer of them: (1) not at all; (2) somewhat; (3) moderately so; (4) very much so. Second subscale (T-anxiety) has also (20) phrases which are evaluate how students feel in general about anxiety, also the second subscale has (4) point which are: (1) almost never; (2) sometimes; (3) often; (4) almost always. After adjusting some paragraphs of the scale, its reliability value reached 0.75 , which is considered high and appropriate.

\section{Cumulative Grade Point Average (CGPA)}

Cumulative Grade Point Average (CGPA) is to measure students' academic achievement.Work within this rating is done at A'Sharqiyah University in the Sultanate of Oman, to justify the level of achievement or student performance, which includes less than 2.00 or $>$ than $\mathrm{C}$, meanwhile, the moderate is 2.00 to less than 3.00, while, more than 3.00 to 4.00 considered high score. The following table shows the distribution of (CGPA) and their interpretation. 
(C) Dr. Esam A Majeed Al lawati

Table 1: Explanation/Analysis of STAI and GPA level

\begin{tabular}{|c|c|c|c|}
\hline Grade & Value & Interpretation & score scale of STAI \\
\hline A & 4.0 & \multirow[t]{7}{*}{ High } & \multirow[t]{7}{*}{$75<$ STAI } \\
\hline A- & 3.7 & & \\
\hline $\mathrm{B}+$ & 3.3 & & \\
\hline $\mathrm{B}$ & 3.0 & & \\
\hline B- & 2.7 & & \\
\hline $\mathrm{C}+$ & 2.3 & & \\
\hline $\mathrm{C}$ & 2.0 & & \\
\hline $\mathrm{C}-$ & 1.7 & \multirow[t]{4}{*}{ Low } & \multirow[t]{4}{*}{$75>$ STAI } \\
\hline $\mathrm{D}+$ & 1.3 & & \\
\hline $\mathrm{D}$ & 1.0 & & \\
\hline $\mathrm{F}$ & 0.0 & & \\
\hline
\end{tabular}

\section{Procedure of Study}

The current study seeking to impact of psychological anxiety on academic achievement in A'Sharqiyah University. The instrument was distributed to the students, the total sample of students was308 from various specializations in A'Sharqiyah University. The STAI scale content 40 phases and it need about 20-25 minutes to answer for entire scale. After applying the scale to students, the researcher correlated with CGPA of under observation students, this is to measure the degree of academic achievement which are affected by their level of anxiety

\section{Data Analysis}

The impact of psychological anxiety on academic achievement in A'Sharqiyah University was examined by Pearson correlation coefficient. The researcher used the Pearson correlation coefficient to know the normal distribution of the study data. 
(C) Dr. Esam A Majeed Al lawati

\section{Results and Discussion}

The result display important correlation of high study anxiety and slight student's academic achievement.

\section{Distribution of study participants}

A researcher send the instrument to total 308 studentsthrough internet to measure anxiety level and how impact to students' academic achievement. Those Students was selected randomly without any interfered from the researcher. Their ages are ranged between 18 to 22 years old and from the various specializations which are offered by the university, also from different cultural and socio-economic background included in Oman. Students under academic observation are distributed among the five different colleges that the university includes: College of Engineering, College of Law, College of Applied and Health Sciences, College of Business Administration, and finally College of Arts and Humanities. The number of male students under academic observation who participated in the current study reached 140, while the number of female students reached 168 . The following table shows distribution of survey.

Table 2: Distribution of survey participants

\begin{tabular}{|l|l|l|}
\hline Gender & Frequency & Percentage \\
\hline Male & 140 & $45.6 \%$ \\
\hline Female & 168 & $54.4 \%$ \\
\hline
\end{tabular}

\section{The impact of anxiety on students' academic achievement}

The result of the current study, and by using the Pearson correlation coefficient, showed that the standard deviation of STAI reached (11.004) while the mean of STAI $(0.320)$ while the standard deviation of the CGPA was (0.231) and its mean averaged (1.93), where this correlation is considered large, a important association $(\mathrm{p}=0.000)$, the correlation coefficient is slight thru $\mathrm{r}=$ - 
(C) Dr. Esam A Majeed Al lawati

0.239 , and lastly the tastermagnitude yield $n=308$. Therefore, academic achievement was negatively associated with anxiety and the correlation coefficient was low.

On the other hand, the consequence confirmed that students who have extraordinary apprehension levels attain humble academic achievement with apprehension level $>88$ and academic achievement $<2.0$. Therefore, it can be reached that there is an important impact of altitude level of anxiety and weak academic achievement between A'Sharqiyah University students.

The current study result agreed with several previous studies which are found a passive correlation among students who possess a high level of anxiety with CGPA decrease. Besides that, the previous study has discussed this result, which found assured impact among extraordinary marks of students' educational accomplishment and weak apprehension. (Soler, 2005 and McCraty, 2007).

The result upholding with McCraty (2000) where worry shows important character in undergraduate learning and educational achievement. In addition, studies have revealed that high anxiety have a close correlation with low academic achievement among students, however this correlation has some advantages in facing anxiety. In conclusion, the researcher agrees that the high level of anxiety will definitely lead to a marked decline in the achievement level of students. The table below shows this results:

Table 3: Consequence of the Correlation among Anxiety and Academic achievement

\begin{tabular}{|l|l|l|l|l|}
\hline Measures & Standard Deviation & Mean & $\mathrm{R}$ & $\mathrm{P}$ \\
\hline STAI & 11.004 & 0.320 & & \\
\hline CGPA & 0.231 & 1.93 & & \\
\hline STAI-CGPA & & & -0.239 & 0.000 \\
\hline
\end{tabular}


(C) Dr. Esam A Majeed Al lawati

\section{Conclusion}

At the conclusion of the current study, the researcher indicates, through the results of previous studies and general literature on the subject of anxiety, that there is a strong correlation between anxiety and academic achievement for students in general, and for higher education students in particular McCraty (2000). Most of the previous studies indicated that anxiety has great and tremendous damage to the psychological stability of the individual and that these damages include students of higher education, including A'Sharqiyah University students.

A'Sharqiyah University students, like the rest of higher education students in the Sultanate of Oman, suffer from anxiety, so it should be checked from time to time the student's level of anxiety. The current study concluded that the high anxiety of A'Sharqiyah University students leads to a decrease in their achievement level, and the results of the current study supported several previous studies such as (McCraty, 2007 andMcCraty, et al, 2000, Goguen, et al, 2010). Through the results of the current research, the university administration can prepare and implement a pre-test for students who are admitted (first-year students), this test is intended only to measure the level of anxiety of the student, and then it can help students whose results show that they have high anxiety, and they are assisted through Training courses and therapeutic concerns.

Through the result of the current research, which shows an obvious link between the student's anxiety and the achievement level, the higher the score in the STAI test indicates the higher the student's anxiety, the more it leads to a decrease in his/her academic achievement and thus his/her CGPA.

\section{References}

- Aronen. E.T, Vuontella. V, Steenari. M.R, Salmi, J, and Carlson, S. 2004. Working memory, psychiatric symptoms, and academic performanceat school. Neurobiology of Learning and Memory, Elsivier. 83(1) 33-42. Doi:10.1016/j.nlm.2004.06.010

- Brook, C., \& Willoughby, T. (2015). The social ties that bind: Social anxiety and academic achievement across the university years. Youth Adolescence. 44, 1139-1152. 
(C) Dr. Esam A Majeed Al lawati

- Emilien, G., Durlach, C., \& Lepola, U. (2002). Anxiety disorders: Pathophysiology andpharmacological treatment. Basel, Switzerland: Birkhäuser.

- Fosterling, F., \& Binser, M. (2002). Depression, school performance, and the verticality of perceived grades and casual attributions. Personality and Social Psychology Bulletin, 28 (10), 1441-1449. Retrieved from https://epub.ub.unimuenchen. de/15172/1/Depression.pdf.

- Goguen, L., Hiester, M., \& Nordstrom, A. (2010) Associations among peer relationships, academic achievement, and persistence in college. Journal of College Student Retention, 12(3), 319-337.

- Mahmoud, J. R., Staten, R., Lennie, T. A., \& Hall, L. A. (2015). The relationships of coping, negative thinking, life satisfaction, social support, and selected demographics with anxiety of young adult college students. Journal of Child \& Adolescent Psychiatric Nursing, 28(2), 97 108.

- McCraty, R. (2007). When Anxiety Causes Your Brain to Jam, use Your Heart. Institute of Heart Math. HeartMath Research Center, Institute of HeartMath, Boulder Creek, CA.

- McCraty, R., Dana, T., Mike, A., Pam, A, and Stephen, J. (2000). Improving Test-Taking Skills and Academic Performance in High School

- Nail, J., Christofferson, J., Ginsburg, G., Drake, K., Kendall, P., McCracken, J., \&Sakolsky, D. (2015). Academic impairment and impact of treatments amongyouth with anxiety disorders. Child \& Youth Care Forum, 44(3), 327-342.

- Pascarella, E., \& Terenzini, P. (2005). How college affects students: A third decade of research (Vol. 2). San Francisco: Jossey-Bass

- Ruffin, P. (2007). A Real Fear: It's More Than Stage Fright, Math Anxiety can Derail Academic or Professional Success, But Some Scholars are Working to Help Students Get over It. Diverse Issues in Higher Education. Findarticle.com (online) http://findarticles.com/p/articles/mi.

- Russell, G., \& Shaw, S. (2009). A study to investigate the prevalence of social anxiety in a sample of higher education students in the United Kingdom. Journal of Mental Health. 18(3), 198-206.

- Sena, Whitaker, Lowe, Patricia, Lu, and Steven. 2007. Significant predictors of test anxiety among students with and without learning disabilities. Journal of Learning Disabilities, 40 (4), 360-376

- Sharma, R., \& Sharma, P. (2015). A correlational study to assess the relation of anxiety and social phobia with academic performance of students in a selected nursing college. International Journal of Nursing Education, 7(2), 26-30. doi:10.5958/09749357.2015.00067.7 